\title{
Derechos innominados en el sistema interamericano
}

\author{
Edgar Fabián Garzón-Buenaventura*
}

\footnotetext{
Doctorando en Derecho, Universidad Libre de Colombia. Coordinador de línea de tendencias contemporáneas de Derecho procesal, Universidad Cooperativa de Colombia, sede Bogotá, Colombia.

Correo electrónico:

edgar.garzon@campusuuc.edu.co
}

Recibido: 14 de enero del 2016

Aprobado: 10 de junio del 2016

Cómo citar este artículo: Edgard Fabián Garzón-Buenaventura. Derechos innominados en el sistema Interamericano. DIXI 24.

Octubre 2016. Pág. 11. doi: http://dx.doi. org/10.16925/di.v18i24.1520

\section{Resumen}

Introducción: el presente artículo de investigación tiene como eje temático la aplicación del control de convencionalidad ejercido por la Corte Interamericana de Derechos Humanos y su recepción en los jueces, los funcionarios jurisdiccionales y las autoridades públicas, la aplicación de garantías en materia de derechos innominados, así como la creación del activismo judicial a través del derecho a la educación como materia jurisdiccional local dentro de los países miembros americanos, y cómo estos arremeten en grave violación colectiva. $M e$ todología: con el fin de analizar esta temática, es necesario irradiarla en el ordenamiento jurídico mexicano y colombiano, de modo que jueguen un papel imperativo en el propósito de derivar su origen y sus causas, entre las que se encuentran: 1 . Del bloque de constitucionalidad al bloque de convencionalidad; 2 . La internacionalización de los derechos humanos; 3. La convencionalización del Derecho; 4. Circulación judicial del precedente; y 5 . Derechos innominados. Resultados: todo esto es consecuencia de las normas de textura abierta descritas en la Declaración Americana y Convención Americana de Derechos Humanos, y un fuerte compromiso en torno al Derecho internacional de los derechos humanos. Conclusiones: lo anterior exige una interpretación hermenéutica de los casos interpartes y sus efectos irradiadores en la sentencia para los países americanos.

Palabras claves: constitución, convención americana, derechos innominados, sistema interamericano, soberanía. 


\title{
Innominate Rights in the Inter-American System
}

\begin{abstract}
Introduction: The central theme of this research article is the implementation of conventionality control exercised by the Inter-American Court of Human Rights and its reception by judges, judicial officials, and public authorities. Other core topics include the implementation of guarantees of innominate rights, and the creation of judicial activism through the right to education as a local jurisdictional matter within the American member countries, as well as how these member countries have lashed out in serious collective violation. Methodology: In order to analyze these issues, it is necessary to place them in the context of Mexican and Colombian law to demonstrate the necessary role of these legal systems in the determination of the issues' origin and causes, which include: 1) the transition from a block of constitutionality to a block of conventionality; 2) the internationalization of human rights; 3 ) the conventionalization of law; 4) transjudicial communication on precedent; and 5) innominate rights. Results: All of the above is a result of the open-textured norms of the American Declaration and American Convention on Human Rights, as well as a strong commitment to international human rights law. Conclusions: A hermeneutical interpretation of inter partes cases and their effects on sentencing for the American countries is needed.
\end{abstract}

Keywords: constitution, American Convention, innominate rights, Inter-American System, sovereignty.

\section{Direitos inominados no sistema interamericano}

\section{Resumo}

Introdução: o presente artigo de pesquisa tem como eixo temático a aplicação do controle de convencionalidade exercido pela Corte Interamericana de Direitos Humanos e sua recepção nos juízes, nos funcionários jurisdicionais e nas autoridades públicas, a aplicação de garantias em matéria de direitos inominados, bem como a criação do ativismo judicial por meio do direito à educação como matéria jurisdicional local dentro dos países membros americanos, e como esses cometem grave violação coletiva. Metodologia: com o objetivo de analisar essa temática, é necessário irradiá-la no ordenamento jurídico mexicano e colombiano, de modo que desempenhem um papel imperativo no propósito de derivar sua origem e suas causas, entre as quais se encontram: 1) do bloco de constitucionalidade ao bloco de convencionalidade; 2) a internacionalização dos direitos humanos; 3 ) a convencionalização do Direito; 4) circulação judicial do precedente; e 5) direitos inominados. Resultados: tudo isso é consequência das normas de textura aberta descritas da Declaração Americana e Convenção Americana de Direitos Humanos, e um forte compromisso em torno do Direito internacional dos Direitos Humanos. Conclusões: isso exige uma interpretação hermenêutica dos casos inter partes e seus efeitos irradiadores na sentença para os países americanos.

Palavras-chave: constituição, convenção americana, direitos inominados, sistema interamericano, soberania. 


\section{INTRODUCCIÓN}

Con la noción filosófica de los derechos humanos, desde la concepción clásica del iusnaturalismo, pasando por el mundo helénico con Antígona, la filosofía cristiana, la descripción del despotismo ilustrado en el siglo de las luces, la descripción formal de las declaraciones occidentales de independencia y derechos del hombre y del ciudadano, es posible reconocer en la Constitución de Cádiz de 1812, la Constitución de Querétaro de 1917 y la Constitución de Weimar de 1919, el paradigma de un reconocimiento único internacional de los derechos humanos. Estos derechos surgen en un inicio como ideas promulgadas por la Organización Panamericana y la Sociedad de las Naciones, con el fin de dar apertura a un verdadero Derecho internacional de los derechos humanos a partir de la carta de Londres de 1945 (Tribunal Nuremberg).

La internacionalización del Derecho permite el surgimiento de los sistemas regionales de protección de derechos humanos, de manera que en este caso concreto se estudiará el Sistema Interamericano de Derechos Humanos y el surgimiento de los derechos humanos innominados, como prevención a la masiva violación de los Estados americanos a la responsabilidad internacional por violación de los mismos.

De acuerdo con lo anterior, es imperioso observar la facultad con la que cuentan, tanto la Comisión Interamericana ${ }^{1}$, como la Corte Interamericana de Derechos Humanos ${ }^{2}$ : ser legislador positivo para resolver los casos difíciles ${ }^{3}$ al construir, a través de su jurisprudencia, derechos que no están descritos en la Convención Americana de Derechos Humanos, o convenciones que permiten fungir el sistema interamericano. En el propósito de seguir un hilo conductor y metodológico, se tomará el derecho innominado a la educación, y su recepción internacional-nacional, nacional-internacional.

\section{MetodologíA}

El artículo desarrolla una metodología cualitativa con un enfoque descriptivo-hermenéutico, seleccionando un trabajo esquemático desde las concepciones

\footnotetext{
1 Entiéndase la función de protección por medio de las medidas cautelares, informes y recomendaciones.

2 Entiéndase sentencias, medidas provisionales, opiniones consultivas y supervisión de cumplimiento de sentencias.

3 Véase la decisión judicial de Hart-Dworkin en la que se resuelven mediante reglas y principios.
}

de los derechos humanos y la irradiación de los paradigmas del sistema interamericano en una nueva construcción jurídica de derechos, tales como la nacionalidad interamericana, la orientación sexual y el derecho al servicio de educación.

\section{DesarRollo}

\section{A. Del bloque de constitucionalidad al bloque de convencionalidad}

El bloque de constitucionalidad tiene su asentamiento en el Derecho francés, más concretamente en la constitución de la v República de Francia de 1958, y en el fallo del Consejo Constitucional del 16 de julio de 1971, en el cual se determina el objeto vinculante del preámbulo constitucional como la interpretación de los principios fundamentales de la república en el control de constitucionalidad. De esto se toma que el bloque de constitucionalidad corresponde a normas de contenido implícito que no están descritas en el texto constitucional, pero, dada su naturaleza jurídica, son fuerza directa para la aplicación del Derecho. Las normas jurídicas que, a pesar de no ser constitucionales, integran parte del bloque de constitucionalidad, pueden dar lugar a que se produzca la declaratoria de inconstitucionalidad de una ley por constituir una violación directa de la constitución.

En el Derecho español, la Constitución Española de 1978 (Artículos 148 y 149), así como la sentencia del tribunal constitucional en el fallo STC 10/82, recuerdan que dicho tribunal se refirió al bloque como "un conjunto de normas que ni están incluidas en la Constitución ni delimitan competencia, pero cuya infracción determina la inconstitucionalidad de la ley sometida a examen"4.

Así, la recepción del bloque de constitucionalidad ha permeado un sistema coherente e integral en las diferentes fuentes innominadas de las normas, forjando un orden global funcionalista, el cual permite extrapolar al intérprete jurídico un análisis sistemático de un derecho comparatista. Esto, si se toma como ejemplo el ordenamiento jurídico colombiano en la norma constitucional de 1991, Artículos 4, 9, 53, 93, 94,102 y 214 .

Todo lo anterior satisface ampliar el marco, en el espectro del derecho a las garantías judiciales,

\footnotetext{
4 Véase Tribunal Constitucional Español. sTC 29/1982 (JC, vol.
} III, 13 de enero de 1982). Pág. 371. 
no solo formales, sino sumergidas en la eficacia de la interpretación dialéctica del juez convencional al juez constitucional, y del juez constitucional al juez convencional, lo cual deja como un hecho obligatorio y vinculante la jurisprudencia en instancias internacionales y una interpretación extensa y acorde con el bloque de constitucionalidad.

La Suprema Corte de la Nación, declara:

El artículo 1o. de la CPEUM vigente a partir del once de junio de dos mil once establece que todas las autoridades, dentro del ámbito de sus competencias, deben promover, respetar, proteger y garantizar los derechos humanos contenidos en la Constitución Federal $\mathrm{y}$ en los tratados internacionales suscritos por el Estado Mexicano. Conforme al ámbito competencial de los juzgadores de amparo, les corresponde de forma relevante la protección de los derechos humanos, ya que su función primordial consiste en ejercer dentro de esa materia un control directo o concentrado de convencionalidad y constitucionalidad. Por otra parte, también existe una vertiente de control difuso o incidental ejercido por el resto de los Jueces del país, los cuales pueden analizar ex officio si las normas generales relacionadas con los procesos de su conocimiento vulneran algún derecho humano reconocido en el bloque de constitucionalidad; en cuyo caso deben inaplicar la norma transgresora, sin necesidad de verificar si podría ser impugnada a través del amparo. Pues bien, si los Jueces comunes cuentan con tan amplias facultades de control de convencionalidad y constitucionalidad de leyes, no puede sostenerse que carezcan de ellas los tribunales de amparo. Por el contrario, como principales garantes de los derechos humanos, pueden ejercer oficiosamente ese control sobre la norma general aplicada en el acto reclamado, aunque no haya sido reclamada o, habiéndolo sido, resulte improcedente el amparo en su contra. En efecto, lo anterior sólo impediría el otorgamiento de la protección federal contra la ley inconvencional o inconstitucional, pero no contra el acto concreto, como medida tendiente a lograr la desaplicación de aquella norma abstracta. Este criterio se encuentra orientado por el principio hermenéutico pro homine establecido en el referido artículo 1o., en virtud del cual debe acudirse a la interpretación más extensiva cuando se trata de fijar los alcances de los derechos humanos y sus garantías ${ }^{5}$.

Lo anterior permite internar una supremacía convencional de la carta interamericana en la Corte

Véase Suprema Corte de la Nación. XxviI, $1 .^{\circ} 10 \mathrm{a} 14 \mathrm{a}$ 6110a (abril 20 del 2015). Pág. 2413.
Interamericana de Derechos Humanos, y es la de colegir de un bloque de constitucionalidad (aún bloque de convencionalidad), decisiones y pronunciamientos tales como: 1 . Sentencias; 2 . Medidas provisionales; 3. Recomendaciones; 4 . Opiniones consultivas; 5 . Supervisiones de cumplimiento hasta un efecto extensivo; y 6. Medidas cautelares pronunciadas por la Comisión Interamericana de Derechos Humanos.

Esto_indica un corpus iuris interamericano (bloque constitucional/ bloque convencional), partiendo del presupuesto que no es un sistema jerárquico sino funcionalista-complementario, el cual se mueve entre la validez normativa, la eficacia y la justicia. Es por esto que traspasa el compromiso normativo del tratado a la aplicación material de los efectos de la sentencia, o a los diferentes mecanismos procedimentales transnacionales que efectúa la Comisión Interamericana de Derechos como organismo cuasi jurisdiccional, o la Corte Interamericana de Derechos Humanos como organismo jurisdiccional.

La Corte Interamericana de Derechos Humanos (IDH) declara:

Por lo tanto, el bloque de constitucionalidad debe entenderse como: "el estándar mínimo" creado por la Corte IDH, para que en todo caso sea aplicado el corpus iuris interamericano y su jurisprudencia en los Estados nacionales que han suscrito o se han adherido a la CADH y han reconocido la competencia contenciosa de la Corte IDH; es un estándar que las propias Constituciones o la jurisprudencia nacional pueden válidamente ampliar, para que también formen parte del "bloque de constitucionalidad/convencionalidad" otros tratados, declaraciones e instrumentos internacionales, así como informes, recomendaciones, observaciones generales y demás resoluciones de los organismos y tribunales internacionales ${ }^{6}$.

Lo que acarrea la reformulación de las fuentes del Derecho, no solo formales, sino también materiales, en un Derecho primigenio, unido no a la coerción, sino a la eficacia real de la justiciabilidad al tenor de las garantías americanas. Al partir del presupuesto que en el siglo Xxi estas ideas se satisfacen con el concepto de la circulación judicial, cuando en el proceso intercomunicacional los jueces no encuentran una coherencia jurídica en el lenguaje normativo de su explicación, y sea en el proceso del trasplante jurídico,

6 Véase Corte Interamericana de Derechos Humanos. Sentencia DE 26 DE NOviembre Del 2010 (Cabrera García Montiel vs. México, noviembre 26 del 2010), voto Razonado Eduardo Ferre Mac-Gregor. 
o en el proceso de ensamblaje de escala mundial del precedente independiente, su estructura (civil law o common law) impacta en el proceso argumentativo jurídico al denotar respuestas en el Derecho.

Ahora bien, esa difusión de prácticas y modelos institucionales presentan distintos tipos de casos. Numerosas estructuras nacionales, por ejemplo, se vieron influenciadas por el clásico modelo tripartito para la regulación en asuntos laborales mediante la negociación cooperativa entre representantes, sindicales y gubernamentales, que hoy en día forma parte constitutiva de la огт (Organización Internacional del Trabajo).

Todo esto lleva a concluir que es necesario pasar del límite entre el Estado nación y el Estado globalizador, a una interacción en un Estado internacional del Derecho.

\section{B. Internacionalización del Derecho de los derechos humanos}

A fin de entablar una explicación de los derechos humanos, sería necesario decir que existe una explicación iusnaturalista, liberal, racionalista, contractualista, marxista e universal. Para explicar cada una de estas etapas, es necesario derivar una concepción materialista histórica, desde el asentamiento del origen de la especie de los homínidos a partir de la era neolítica, hasta el homo sapiens. Esto permite un reconocimiento social del mundo griego en las ciudades-estados ${ }^{8}$, pasando al mundo romano con estoicos tales como Séneca, Epicuro o Marco Tulio, $y$, finalmente, en el Medioevo se reconocen con Santo Tomás de Aquino unos derechos humanos trascendentales. Así, con la teoría liberal racionalista conocida como despotismo ilustrado-, se pasa del plano teórico al plano pragmático con la Declaración de los Derechos de Virginia del 12 de junio de 1776, y la Declaración de los derechos del hombre y del ciudadano del 26 de Agosto de 1789. Estas teorías liberales entran en crisis en el siglo xx en la dimensión de los derechos económicos, sociales y culturales de la Declaración de los derechos del pueblo trabajador y explotado de la revolución marxista en 1918, de los cuales se pueden tomar como ejemplo las dos

Véase Sakia Sassen. Territorio, AUtoridad y Derechos. Editorial Katz. (2010).

8 Entiéndase Atenas, Esparta y Tebas, cada una con un sistema político diferente (democracia, monarquía y aristocracia). dimensiones en la Constitución de México de 1917 y la Constitución de Weimar de 1919. De esta manera, el núcleo esencial de los derechos humanos es una concepción histórica y materialista: "Los derechos humanos están marcados por sangre y es un reconocimiento personal y social hacia el Estado que tiene su fragmento en la guerra"

Sin embargo, este giro copernicano se da gracias a la influencia de tres elementos estructurales: 1. El nacimiento de la supremacía constitucional; 2. Relación entre reglas y principios constitucionales; y 3. El activismo judicial de los modelos continentales europeos y el control norteamericano. Ferreres aclara al respecto:

A los derechos fundamentales hay que atribuirles un significado concreto se proyectan a los diversas problemas que afloran en una sociedad cambiante. Hay que tener en cuenta las posibles, pues las reglas operativas en los principios abstractos deben tener permanencia y formar un todo coherente. Para el correcto desarrollo de esta tarea profundamente intelecto es necesario un ambiente de paz y tranquilidad ${ }^{10}$.

A fin de explicar los trasfondos de la internacionalización del Derecho, es necesario apartarse de sus dos contenidos: 1 . Neoconstitucionalismo transformador; 2. Globalización del derecho. Al distinguir el primero como el resurgimiento en los ordenamientos constitucionales occidentales del acápite de los derechos humanos, con la descripción formal de los derechos fundamentales se hace necesario repensar el texto constitucional, no solo como una norma programática de producción normativa y jerárquica que irradia las diferentes materias del Derecho, sino a su vez como la interpretación constitucional en la que la capacidad deductiva de los jueces lleva a la solución de los casos difíciles (reglas, principios, valores y directrices), por medio de la herramienta del test de proporcionalidad. Esto hace posible la creación jurídica de sentencias legislativas, las cuales permiten crear la teoría de los derechos innominados por la materialización de la influencia de las cortes nacionales, ya sean en el control difuso de constitucionalidad - como es el caso de México-, o las cortes constitucionales como en el caso de Ecuador con el control concentrado de constitucionalidad.

\footnotetext{
9 Véase Rudolf von Ihering. LA LUCHA POR EL DERECHO. Editorial Trotta. (2005). Pág. 14.

10 Véase Víctor Ferreres. UnA DEFENSA DEL MOdelo EuRopeo de control de Constitucionalidad. Marcial Pons. (2011). Pág. 70 .
} 
De esta manera, gracias a las influencias del precedente se consolida un reconocimiento de los derechos humanos como derechos fundamentales dotados de fuerza vinculante.

De acuerdo con Ávila:

El neoconstitucionalismo, sin ánimo de agotar la discusión ni de elaborar un concepto acabado, no es otra cosa que la teoría de los derechos fundamentales puesta en el centro de la teoría del derecho y del Estado. El derecho se construye ya no a partir de la ley, de la propiedad, del mercado, de la autonomía de la voluntad, del derecho subjetivo, del Estado, de orden público, de los principios generales, de la civilización, del progreso; sino que debe construirse a partir de las personas y colectividades y de sus derechos. En este sentido, la teoría del derecho ya no puede ser el título preliminar del Código Civil y la teoría del estado no debe ser solo la institucionalidad y la organización del poder. Los derechos fundamentales son un medio y al mismo tiempo el fin de la teoría, del Estado y de la organización social. Al neoconstitucionalismo hay que agregarle la palabra "transformador", y esto significa ya una posición política. El neoconstitucionalismo transformador pretende alterar la realidad, que es de exclusión, marginalidad y discriminación, y la transformación de un sistema y una forma de vida "colonizada" a una de emancipación y liberación de las grandes mayorías de la población, que no pueden ejercer sus derechos y que el Estado les ofrece políticas paternalistas o simplemente represión penal ${ }^{11}$.

Esto sobrepasa una relación en torno a una teoría de los derechos fundamentales en la que, de acuerdo con el maestro italiano, "todos aquellos derechos subjetivos que corresponden universalmente a todos lo seres humanos en cuanto dotados de status de personas, ciudadanos o de personas con capacidad obrar"12.

Esta teoría tiene un doble componente que se sincroniza con los derechos humanos, lo cual genera uno de los efectos en la globalización del Derecho en el plano teórico, entendiéndose esta globalización como un proceso en cuyo despliegue intervienen, tanto las grandes transformaciones que se han presentado en las sociedades, como la influencia que han ejercido ciertos actores, de manera que constituye un fenómeno activo y organizado - especialmente

11 Véase Ramiro Ávila Santamaría. En Defensa Del Neo constitucionalismo Andino. Corporación de Estudios y Publicaciones-CEP. (2014). Pág. 7.

12 Luigi Ferrajoli. Títulu. Editorial. (1999). Pág. 37. de largo tiempo- que no representa un fenómeno externo a las sociedades, sino una dinámica transversal que rebasa las fronteras y posibilita complejas compenetraciones.

\section{Convencionalización del Derecho}

La convencionalización del Derecho se forja a través de la representación del sistema interamericano, la aproximación conceptual y la creación innominada de derechos humanos tales como desplazamiento forzado, libertad sexual, debido proceso administrativo, y el eje temático derecho a la educación, a través del instrumento operativo de creación normativa y jurisprudencial del control de convencionalidad. Ahora bien, hay que decir que la aceptación de los acuerdos y cada uno de los tratados internacionales ratificados por México y Ecuador mediante el Decreto 2768 de 1984, tal como lo es el Pacto de San José de Costa Rica por medio de sus Artículos 1 y 2, hace mención de un control directo de convencionalidad:

Art 1. Los Estados partes en esta Convención se comprometen a respetar los derechos y libertades reconocidos en ella y a gozar su libre y pleno ejercicio a toda persona que esté sujeta a su jurisdicción, sin discriminación alguna por motivos de raza, color, sexo, idioma, religión, opiniones políticas o de cualquier otra índole, origen nacional o social, posición económica, nacimiento o cualquier otra condición social.

Art 2. Si en el ejercicio de los derechos y libertades mencionados en el artículo 1 no estuviere ya garantizado por disposiciones legislativas o de otro carácter, los Estados partes se comprometen a adoptar, con arreglo a sus procedimientos constitucionales y a las disposiciones de esta Convención, las medidas legislativas o de otro carácter que fueren necesarias para hacer efectivos tales derechos y libertades ${ }^{13}$.

En el sistema interamericano, el funcionamiento jurisdiccional de la competencia contenciosa de la Corte Interamericana de Derechos Humanos ha permitido - a través de la figura del control de convencionalidad-, el reconocimiento de derechos cuando es insuficiente la justicia local nacional. Por tanto, se puede decir que es una acción procesal y un derecho de contenido sustancial, el cual permite determinar y

13 Véase Convención Americana de Derechos Humanos (Pacto de San José). Artículos 1 y 2. Noviembre 7 al 22 de 1969. 
garantizar los derechos humanos de escala internacional a una escala nacional.

Al respecto, Bidart Campos afirma:

Y si se les reconoce carácter jurídico-normativo, demuestran en conjunción con la normativa internacional anidada en los tratados sobre derechos humanos que, si bien tal normativa oriunda de fuente internacional penetra e ingresa en el derecho interno (estatal) para formar parte de él, ingresa desde afuera, con lo que la voluntad del Estado (colaboradora indudable en esa recepción del derecho internacional por el interno que se expresa en la ratificación internacional de los tratados) no es el único ni último hontanar de los derechos humanos que se reconocen en el orden normológico. ${ }^{14}$

Gracias a esto, podríamos decir que es una acción destinada a un control efectivo de los derechos humanos, mediante tres ideas operantes: 1. Aplicación coactiva del precedente del sistema interamericano a la justicia nacional de los Estados americanos; 2. Diálogo interjudicial que permite armonizar los derechos humanos en la jurisdicción local; 3. Interpretación y creación jurídica de derechos innominados.

El control de convencionalidad es la figura gracias a la cual los jueces estudian la compatibilidad de una norma nacional con las disposiciones interamericanas. En este orden de ideas, este examen le corresponde primariamente a la propia Corte IDH (control concentrado). No obstante, según los más recientes avances jurisprudenciales, su ejercicio también les compete a los jueces nacionales que ejercen control de constitucionalidad o, en general, a cualquier funcionario judicial (control difuso). En ejercicio de su función de protección en el marco de los procesos contenciosos, la Corte IDH estudia, tanto la adecuación del comportamiento de los agentes estatales, como del ordenamiento nacional a las obligaciones interamericanas, con el objetivo de decidir si el Estado ha incurrido o no en responsabilidad internacional y, en consecuencia, determinar las secuelas de la violación (esto es, el alcance de la reparación). Es en este escenario en el que se practica, en estricto sentido, el control de convencionalidad. Desde su primer uso en el caso Almonacid, el órgano judicial regional se ha referido al control de convencionalidad en 20 casos

14 Véase Germán J. Bidart Campos. Teoría general De los Derechos humanos. Universidad Nacional Autónoma de México. (1989). Pág. 430. contenciosos 138, recomendaciones y supervisiones de cumplimiento.

Tomemos como punto de partida las normas sobre jerarquía, complementariedad y armonización a nivel nacional. Gracias a estas, los jueces nacionales pueden servirse del Derecho internacional como fundamento de sus decisiones o, por lo menos, como referente en el ejercicio hermenéutico que adelantan. Sumado a este marco constitucional de recepción y armonización, se encuentran los Artículos 1.1 y 2 de la convención, así como el Artículo 29 de la misma. Estas normas vienen a reforzar las disposiciones nacionales sobre jerarquía e interpretación, allí donde ellas existen, o bien a llenar el vacío que deja su ausencia en los ordenamientos que no las contemplan. Así, pues, los jueces nacionales se sirven del Derecho internacional de los derechos humanos como norma constitucional o supra-legal.

$\mathrm{Al}$ respecto, la Corte IDH reitera en el caso de Cabrera García y Montiel Flores vs. México, que si bien la protección internacional resulta "de naturaleza convencional coadyuvante o complementaria de la que ofrece el derecho interno de los Estados americanos", como se expresa en el "Preámbulo" de la CADH (principio de subsidiariedad que también ha sido reconocido desde el inicio de su propia jurisprudencia), lo cierto es que a fin de realizar un análisis valorativo del cumplimiento de determinadas obligaciones internacionales, "existe una intrínseca interrelación entre el análisis del derecho internacional y de derecho interno"15. Esta "interacción" se convierte, en realidad, en una "viva interacción" con intensos vasos comunicantes que propician el "diálogo jurisprudencial”, en la medida en que ambas jurisdicciones (la doméstica y la internacional) necesariamente deben atender a la normativa "nacional" y a la "convencional" en determinados supuestos. Así sucede, a modo de ejemplo, con la valoración sobre la legalidad de una detención. La actuación de los órganos nacionales (incluidos los jueces), además de aplicar la normativa que los rige en sede doméstica, tienen la obligación de seguir los lineamientos y pautas de aquellos pactos internacionales que el Estado, en uso de su soberanía, reconoció expresamente, y cuyo compromiso internacional asumió.

En caso de no lograr esa interpretación, según sus propias competencias, deberán, o bien abstenerse de usar la norma, o bien expulsarla del ordenamiento jurídico (control de constitucionalidad/convencionalidad). Se trata, en todo caso, de ejercicios de armo-

15 Véase Corte Interamericana de Derechos Humanos, supra, nota 6. Párr. 16. 
nización que, con efectos diferentes, procuran la protección efectiva de los derechos humanos. En aquellos escenarios en los que las normas interamericanas han adquirido un rango constitucional o supralegal, el bloque de convencionalidad se subsume en el bloque de constitucionalidad y, por lo tanto, el ejercicio de todo control de constitucionalidad resulta ser, a su vez, un ejercicio de control de convencionalidad.

\section{Aplicación coactiva del precedente del sistema interamericano a la justicia nacional de los Estados americanos}

En el propósito de forjar una relación más pragmática en torno a los derecho humanos, no solo consta la responsabilidad al Estado cuando este quebranta la Convención Americana y este sea el legitimado por pasiva de la naturaleza jurídica procesal; la Corte Interamericana de Derechos Humanos ha hecho extensiva la teoría de la interpretación vinculante del precedente de los Estados que deben aplicar jueces, órganos jurisdiccionales y ministerio público. Así, aunque el Estado no sea el infractor de la convención, debe aplicar las interpretaciones que se efectúan en torno a la protección de la norma convencional, lo cual nos lleva a deducir un Derecho judicial americano, unificando la jurisprudencia en eje de lo humano a lo fundamental.

La Corte Interamericana de Derechos Humanos, declara (2012):

Los jueces y órganos vinculados a la administración de justicia en todos los niveles están en la obligación de ejercer ex officio un "control de convencionalidad" entre las normas internas y los tratados de derechos humanos de los cuales es parte el Estado, evidentemente en el marco de sus respectivas competencias y de las regulaciones procesales correspondientes. En esta tarea, los jueces y órganos vinculados a la administración de justicia, como el ministerio público, deben tener en cuenta no solamente la Convención Americana y demás instrumentos interamericanos, sino también la interpretación que de estos ha hecho la Corte Interamericana. ${ }^{16}$

De esto surgen dos ideas: (a) La interpretación conforme a la luz del efecto irradiador de las

16 Véase Corte Interamericana de Derechos Humanos. Caso Gudiel Álvarez y otros ("Diario Militar") vs. Guatemala. Sentencia 20 de Noviembre de 2012. Fondo Reparaciones y Costas. sentencias; (b) Un derecho ius comune. En el primero el juez debe declarar oficiosamente, o a solicitud de parte, la inconvencionalidad de la ley de un acto administrativo o de la misma Constitución, cuando esta vulnere la convención o demás tratados en materia de derechos humanos, hasta el precedente en las sentencias jurisdiccionales que crean derechos, llevando a esto un derecho ius comune bajo un precedente vertical a la jurisdicción nacional. El problema es una cuestión mediática: ¿si una norma es inconvencional, cuáles podrían ser sus efectos inter-partes o erga omnes?, toda vez que al declarar la convencionalidad por medio de la facultad jurisdiccional, esta se mantendría, siguiendo la persistencia del daño y la vulneración del derecho humano americano.

De acuerdo con Sagüés:

Mediante el uso de la interpretación "conforme", el operador puede a menudo evitar la declaración de invalidez, por "inconvencionalidad", de normas constitucionales o subconstitucionales prima facie colisionantes con el Pacto de San José de Costa Rica. Se trata de un dispositivo práctico de rescate de esas normas, podrían permanecer como válidas, en tanto y en cuanto se seleccione, para carlas, sus interpretaciones posibles "conformes" con la Convención Americana y se descarten las interpretaciones conflictivas con la misma Convención, o con jurisprudencia de la Corte ${ }^{17}$.

Este permite la consolidación del Derecho no a través de la ley, sino a través de la creación pretoriana, generando nuevas formas para que este se manifieste, lo cual va de la globalización del Derecho, a una manifestación de la globalización judicial en la circulación judicial o los diálogos entre cortes.

\section{E. Circulación judicial del precedente}

A partir del siglo $\mathrm{xx}$ - sostienen los comparatistas (entre ellos el maestro Lucio Pegoraro y Peter Haberle) - cuando el Derecho deja de ser una reciprocidad autóctona de los Estados, algunas teorías, a fin de responder a problemáticas sociales, viajan por las fuente judiciales. Todo esto genera un cambio de mentalidad en la que la civil law y la common law se fusionan, generando estructuras en los ordenamientos occidentales y cambios significativos en el siglo xx. De este modo, después de la posguerra

17 Véase Néstor Sagüés. OBLIGACIONES INTERNACIONALES y Control de Convencionalidad. Opus Magna. (2011). Pág. 286. 
se transforma la noción del Derecho: 1. Las constituciones occidentales después de la segunda guerra mundial describen un iusnaturalismo, dejando las cartas magnas no solo como normas programáticas, sino con mandatos de eficacia directa; 2 . La reelaboración y protagonismo en la interpretación de un órgano especializado en el control de constitucionalidad y supremacía de la carta magna; 3. Integración y consolidación de un Derecho internacional público (Derecho comunitario-Derecho internacional de los derechos humanos); 4. Protagonismo del precedente internacional en materia responsabilidad del Estado (control de convencionalidad) concentrado-difuso; y 5. Desarrollando teorías miméticas (margen de apreciación nacional-incidente de sostenibilidad fiscal).

Por su parte, Brito, Rodrigo y Carbonell afirman:

La labor de los jueces implica entonces la recreación del derecho en el hecho, y por ende es un vehículo cardinal del sistema normativo, ya que a través de la interpretación que hacen los órganos jurisdiccionales, se logra la afirmación del ordenamiento jurídico, a través de la resolución de situaciones particulares. Esta interpretación conforme a los tratados, internacionales, por tanto hace que los jueces nacionales deben tomar en cuenta el desarrollo que se hace de los derechos en los instrumentos de carácter internacional. ${ }^{18}$

Esto renueva, modifica e incluye nuevos ingredientes (mandatos normativos), dejando así en el baúl de los recuerdos los elementos nacionales, la supremacía del orden constitucional, la soberanía y la creación legislativa.

Con relación a esto, López afirma:

En teoría del derecho, como en muchas otras áreas del derecho, estos países trasplantan o usan ideas originarias en jurisdicciones prestigiosas. Estas jurisdicciones prestigiosas, según los comparativistas, son las figuras parentales de las familias jurídicas. Las jurisdicciones periféricas son los hijos de familia, y su misión, como en las familias humanas, es aprender mediante mimesis de sus padres. ${ }^{19}$

Esto permite una relación, un activismo judicial global denominado "diálogos judiciales", los cuales

18 Véase Rodrigo Brito y Miguel Carbonell. La GLOBALIzACión Y LOS DERECHOS HUMANOS, A LA LUZ DE LA REFORMA CONSTITUCIONAL DE JUNIO DE 2011. UNAM. (2011). Pág. 19.

19 Véase Diego López. Teoría Impura del Derecho. Legis. (2012). Pág. 17. son de dos especies: 1 . Cortes internacionales-cortes nacionales; y 2. Cortes nacionales-cortes internacionales.

A veces, las sentencias nacionales resultan ser aún más benéficas, ya que a raíz de esto se aplicarán al principio pro homine, permitiendo una sincronización en el eje del Derecho, y más en el Derecho internacional de los derechos humanos.

A partir de todo esto surge la relación del diálogo judicial, cuando dos o más personas quieren discutir y buscan llegar a acuerdos que se logran a través de la argumentación. Sin embargo, han de respetar unas reglas cuyo seguimiento asegura el diálogo como actividad racional.

El diálogo inter-jurisdiccional ocurre cuando el tribunal receptor de la jurisprudencia la analiza razonadamente, explica y aplica su alcance y significado, así como su alcance en la decisión del caso.

La confrontación con sus propios antecedentes que debe hacer el tribunal que recibe la jurisprudencia a través de un proceso de argumentación, es la que va a permitir el verdadero diálogo jurisprudencial. De esta forma, la jurisprudencia recibida produce una fertilización en la jurisprudencia receptora.

Evidentemente, en el mundo de la globalización del siglo xxi que transitamos, los tribunales internacionales y los tribunales nacionales forman parte de una "red jurídica" de interpretación de los derechos reconocidos por los instrumentos internacionales y el Derecho interno.

En un plano general de discusión, se profundiza un diálogo jurisdiccional entre la CIDH y los respectivos órganos de cierre de la jurisdicción constitucional de Estados que conforman el sistema interamericano, con el fin de que aquella tenga presentes las observaciones o discordancias que los mismos formulen a los criterios jurisprudenciales trazados por el tribunal interamericano, y así ayudar en sus labores jurisdiccionales.

Se aprecia con nitidez que debe referirse a un modelo multinivel de protección de derechos humanos, en el supuesto de una pretendida combinación de las dimensiones nacionales e internacionales, en el propósito de adquirir criterios hermenéuticos.

El diálogo jurisprudencial se constituye en el paradigma jurisdiccional desde el cual contribuir a un complejo proceso que conduzca hacia la real afectividad de los derechos fundamentales. Especificado en el margen interactivo de la defensa multinivel de estos derechos, a partir de una mutua influencia jurisdiccional que respete el importante. 
Entendemos por red aquel conjunto de herramientas, instituciones o personas relacionadas $\mathrm{u}$ organizadas de manera formal o informal, cuyo propósito es la consecución de un determinado fin u objetivo común; en este caso, desarrollar la función judicial que pretende asegurar la protección de los derechos humanos. En nuestro contexto, la red judicial de protección tiene varios niveles. Es decir, se trata de una red construida verticalmente a través de un diálogo de doble sentido, entre lo nacional y lo internacional, pero también en términos horizontales entre las diferentes judicaturas nacionales. La imagen visual de dicha red es la de una telaraña cuyo eje central sería el tribunal regional que, no obstante, hemos de aclarar, no se comporta en términos jerárquicos, sino como punto de referencia común. Por el momento, y dado el enfoque ius internacionalista de nuestro trabajo, y al tener en consideración nuestra hipótesis principal, nos interesa el eje vertical de esta relación. Esto es, nos interesa la construcción de la red, así como sus alcances, desde la relación del juez interamericano con sus homólogos nacionales. En consecuencia, las referencias a la interacción horizontal se limitarán a aquellas necesarias para la comprensión de nuestro objeto de estudio.

Las bases de esta relación se encuentran en los objetivos compartidos y en las diversas cláusulas, las cuales hacen referencia a los instrumentos internacionales de derechos humanos, bien sea para servirse de ellos, o bien como fuente de inspiración, con el fin de requerir la interpretación de las normas constitucionales, complementar el catálogo de derechos fundamentales, reglamentar la forma de incorporarlos o concederles una jerarquía especial dentro del ordenamiento jurídico nacional.

Los diálogos corresponden a una facultad de un activismo de creación pretoriana que permite maximizar en la región americana: 1. La jerarquía de los tratados de derechos humanos sobre las normas nacionales; 2 . Cláusulas abiertas en materia de derechos fundamentales; 3 . Las disposiciones sobre interpretación, en la medida en que son aquellas normas previstas para dar cumplimiento a las órdenes interamericanas.

Las normas sobre jerarquía en materia de derechos humanos permiten estimular la interacción entre los jueces nacionales e internacionales, pues su existencia facilita el uso del Derecho internacional en el contexto local, y matiza los obstáculos propios de la confrontación normativa.

Por otro lado, las herramientas jurisprudenciales en materia de las cláusulas abiertas con relación a los derechos fundamentales, permiten articular el trabajo de ambas jurisdicciones - las cuales son complementarias-: por una parte, la figura del control de convencionalidad creada por el juez interamericano; $\mathrm{y}$, por la otra, la herramienta de la interpretación, en conformidad con la empleada por el juez federal en las acciones de amparo constitucional para la interpretación y creación de los derechos humanos a la luz de los derechos fundamentales, ejerciendo la facultad de los derechos innominados.

Las disposiciones sobre interpretación, en la medida en que son aquellas normas previstas para dar cumplimiento a las órdenes interamericanas, cumplen una facultad de materialización entre las sentencias, las opiniones consultivas, las medidas provisionales y las sentencias de supervisión de cumplimiento, ejerciendo órdenes directas de aplicación armónica y coherencia funcional para los jueces internacionales y nacionales. Esta facultad, que parecía direccionarse en un cumplimiento coactivo o una orden directa de la sentencia, permite actualmente por el diálogo jurisdiccional un cumplimiento facultativo, toda vez que el escenario es propicio en materialización de Derecho internacional de derechos humanos, creando las circunstancias imperiosas de sentencias legislativas en torno a los derechos innominados.

Así, la idea del diálogo interjudicial surge con ocasión de los estudios de Derecho comparado; con ella se pretende describir el creciente uso de la jurisprudencia extranjera e internacional por parte de los jueces como referente para justificar o reforzar sus decisiones.

La herramienta fundamental para lograr una globalización del Derecho es el diálogo entre los jueces que buscan respuestas comunes a problemas comunes. Es posible distinguir tres tipos de diálogos:

- Vertical: entre jueces nacionales e internacionales.

- Horizontal: entre jueces nacionales de diferentes Estados.

- Mixta: entre jueces de uno y otro escenario.

Atendiendo a este marco teórico y en el contexto que se describe en el escenario interamericano se adelanta un diálogo de naturaleza formal y vertical, esto es, un uso mutuo de las normas y la jurisprudencia como resultado de la plena convicción que tienen, tanto los jueces nacionales, como el juez regional, de un objetivo compartido y un marco jurídico de referencia común que debe leerse conjuntamente y los obliga a articularse.

Las mayores pruebas de este diálogo se encuentran en la jurisprudencia — resultado del ejercicio del control de constitucionalidad-, o de los mecanismos 
de protección de los derechos humanos-fundamentales. Por otra parte, y como consecuencia de lo anterior, el proceso de adaptación ha visto incrementados sus resultados y, con ello, la eficacia del andamiaje de protección se ha fortalecido y ampliado.

Veamos algunos ejemplos que dan cuenta de todos estos asuntos. Los alcances del diálogo, producto del conjunto normativo y las herramientas jurisprudenciales, pueden apreciarse en uno de los asuntos que más ha marcado la historia reciente de los derechos humanos en Latinoamérica: los procesos de transición hacia la democracia de varios de los países que se han visto inmersos en dictaduras o quiebres del orden constitucional.

\section{F. Derechos innominados}

Son aquellos derechos que, si bien se encuentran implícitos en el ámbito de protección de distintas disposiciones jurídicas fundamentales, no se encuentran textualmente enunciados en ellas.

Se mencionaba que el neoconstitucionalismo se entiende como la forma moderna de aplicación del Derecho, desde el ámbito de la separación de poderes del Estado y la garantía de los derechos ${ }^{20}$ de los hombres. En este sentido, concede a la jurisprudencia un giro especial al momento de reconocer la materialización intervencionista del Estado para satisfacer el cumplimiento de la protección de los derechos que rezan en la constitución e, incluso, a su vez emerge como criterio para salvaguardar derechos que, si bien no están taxativamente enunciados en la carta magna como tales, por su contenido y naturaleza se entienden como fundamentales.

De acuerdo con Torres Bayona:

Son aquellos derechos implícitos en el ámbito de protección de distintas disposiciones jurídicas constitucionales, pero que, sin embargo, no se encuentran textualmente enunciados en la Carta. La Constitución los consagra pero no los nomina. Clásico ejemplo de este tipo de derechos es el mínimo vital. ${ }^{21}$

20 Véase Declaración de los Derechos del Hombre y del Ciudadano (1789), Artículo 116. Una sociedad en la que no esté establecida la garantía de los derechos, ni determinada la separación de los poderes, carece de Constitución.

21 Véase Torres Bayona. Daniel. Criterios utilizados por la Corte Constitucional para Establecer un catalogo abierto a los derechos fundamentales. Editorial. Universidad Industrial de Santander (2008). Pág. 68
La Corte Interamericana no ha sido ajena a construir una teoría en el eje de los derechos innominados, al proponer líneas jurisprudenciales - desde las convenciones hasta las sentencias-, en el propósito de equilibrar un corpus iuris interamericano, pasando de ser un órgano receptivo, a un órgano de juez legislador convencional, de manera que abarca desde derechos individuales, hasta derechos de contenido social.

Gordon declara en el 2001:

La concepción de justicia social del Estado posrevolucionario fue moldeada por el origen popular de la Revolución y por objetivos de desarrollo. Las concepciones que sostenían los ideólogos revolucionarios se guiaban por una lógica en la que la igualdad de oportunidades para todos favorecería el desarrollo, y éste a su vez traería consigo la justicia social. Desarrollo y justicia social eran vistos como componentes de la misma ecuación: para satisfacer las demandas de las masas populares que habían hecho la Revolución, era preciso impulsar el crecimiento económico del país, lo cual se lograría con más facilidad si se daba a los trabajadores la oportunidad y los medios. Es decir, si algunos bienes de la nación se distribuían equitativamente y otros eran explotados y administrados por el Estado, representante del interés público. ${ }^{22}$

Estas garantías permiten equilibrar la masiva violación en el continente interamericano, ajenas a la recepción sino a la integración jurisprudencial, siendo los jueces los creadores del derecho "Las profecías de que los tribunales harán es lo que entiendo por derecho" 23 en el caso que aborda desde protocolo de San Salvador de los derechos Económicos, Sociales y Culturales Art. 13. El derecho a la Educación a lo que en principio entendido

La Corte Interamericana declara:

Ahora bien, el Comité de Derechos Económicos, Sociales y Culturales ha señalado que para garantizar el derecho a la educación debe velar por que en todos los niveles educativos se cumpla con cuatro características esenciales e interrelacionadas: I) Disponibilidad, II) Accesibilidad, III) Aceptabilidad y IV) Adaptabilidad.

A. Disponibilidad. Debe haber instituciones y programas de enseñanza en cantidad suficiente en el

22 Véase Sara Gordon. CiUdAdANía Y DERECHOS SOCIALES ¿CRIterios distributivos? Clasco. (2001). Pág. 25.

23 Véase Holmes Oliver The PATH of THE LAw. Collected Papers. (1920). Pág. 173. 
ámbito del Estado Parte. Las condiciones para que funcionen dependen de numerosos factores, entre otros, el contexto de desarrollo en el que actúan; por ejemplo, las instituciones y los programas probablemente necesiten edificios u otra protección contra los elementos, instalaciones sanitarias para ambos sexos, agua potable, docentes calificados con salarios competitivos, materiales de enseñanza, etc.; algunos necesitarán además bibliotecas, servicios de informática, tecnología de la información, etc.

B. Accesibilidad. Las instituciones y los programas de enseñanza han de ser accesibles a todos, sin discriminación, en el ámbito del Estado Parte. La accesibilidad consta de tres dimensiones que coinciden parcialmente:

I) No discriminación. La educación debe ser accesible a todos, especialmente a los grupos $\mathrm{m}$ [á]s vulnerables de hecho y de derecho, sin discriminación por ninguno de los motivos prohibidos (...).

II) Accesibilidad material. La educación ha de ser asequible materialmente, ya sea por su localización geográfica de acceso razonable (por ejemplo, una escuela vecinal) o por medio de la tecnología moderna (mediante el acceso a programas de educación a distancia).

III) Accesibilidad económica. La educación ha de estar al alcance de todos. Esta dimensión de la accesibilidad está condicionada por las diferencias de redacción del párrafo 2 del artículo 13 respecto de la enseñanza primaria, secundaria y superior: mientras que la enseñanza primaria ha de ser gratuita para todos, se pide a los Estados Partes que implanten gradualmente la enseñanza secundaria y superior gratuita.

C. Aceptabilidad. La forma y el fondo de la educación, comprendidos los programas de estudio y los métodos pedagógicos, han de ser aceptables (por ejemplo, pertinentes, adecuados culturalmente y de buena calidad) para los estudiantes $y$, cuando proceda, los padres; este punto está supeditado a los objetivos de la educación mencionados en el párrafo 1 del artículo $13 \mathrm{y}$ a las normas mínimas que el Estado apruebe en materia de enseñanza (...).

D. Adaptabilidad. La educación ha de tener la flexibilidad necesaria para adaptarse a las necesidades de sociedades y comunidades en transformación y responder a las necesidades de los alumnos en contextos culturales y sociales variados.

7. Al considerar la correcta aplicación de estas "características interrelacionadas y fundamentales", se habrán de tener en cuenta ante todo los superiores intereses de los alumnos.
La educación ha de tener la flexibilidad necesaria para adaptarse a las necesidades de sociedades y comunidades en transformación y responder a las necesidades de los alumnos en contextos culturales y sociales variados. Por su parte, el Comité de los Derechos del Niño, en su Observación General No. 1 sobre los Propósitos de la Educación, ha señalado que "los métodos pedagógicos deben adaptarse a las distintas necesidades de los distintos niños ${ }^{24}$.

No obstante, estas son las condiciones que conllevan a un objeto de interpretación y creación jurídica que permita evitar la violación grave de derechos humanos de contenido social, tales como el derecho a la educación y la libertad sexual. Por ejemplo, en conformidad con el derecho a la educación de las minorías sexuales, estas deben ser tratadas en igualdad de condiciones con las personas heterosexuales. Una conducta discriminatoria en el ámbito educativo es violatoria de los derechos a la igualdad y a la educación.

La Corte Interamericana de Derechos Humanos se pronunció al respecto:

La Corte Interamericana deja establecido que la orientación sexual y la identidad de género de las personas son categorías protegidas por la Convención. Por ello está proscrita por la Convención cualquier norma, acto o práctica discriminatoria basada en la orientación sexual de la persona. En consecuencia, ninguna norma, decisión o práctica de derecho interno, sea por parte de autoridades estatales o por particulares, pueden disminuir o restringir, de modo alguno, los derechos de una persona a partir de su orientación sexual.

En lo que respecta al argumento del Estado de que para la fecha de emisión de la sentencia de la Corte Suprema no habría existido un consenso respecto a la orientación sexual como categoría prohibida de discriminación, la Corte resalta que la presunta falta de un consenso al interior de algunos países sobre el respeto pleno por los derechos de las minorías sexuales no puede ser considerado como un argumento válido para negarles o restringirles sus derechos humanos o para perpetuar y reproducir la discriminación histórica y estructural que estas minorías han sufrido. El hecho de que ésta pudiera ser materia controversial en algunos sectores y países, y que no sea nece-

24 Véase Corte Interamericana de Derechos Humanos. Sentencia de 1 DE SePtiembre Del 2015. (Lluy vs. Ecuador, septiembre 1 del 2015). Pág. 263. 
sariamente materia de consenso no puede conducir al Tribunal a abstenerse de decidir, pues al hacerlo debe remitirse única y exclusivamente a las estipulaciones de las obligaciones internacionales contraídas por decisión soberana de los Estados a través de la Convención Americana.

Un derecho que les está reconocido a las personas no puede ser negado o restringido a nadie y bajo ninguna circunstancia con base en su orientación sexual. Ello violaría el artículo 1.1. De la Convención Americana. El instrumento interamericano proscribe la discriminación, en general, incluyendo en ello categorías como las de la orientación sexual la que no puede servir de sustento para negar o restringir ninguno de los derechos establecidos en la Convención. ${ }^{25}$

\section{CONCLUSIONES}

Así, se puede decir que bajo el imperio de la convencionalidad, el derecho de la educación pasa de ser una articulación del Protocolo de San Salvador, a establecer un diálogo con la orientación sexual como un derecho humano, que pasa de lo ajeno de los criterios sospechosos y no aceptados por los Estados americanos, en cuanto a interpretación interamericana, constituyéndose en una fuente formal y material del Derecho, tanto de accesibilidad, como de adaptabilidad y de no discriminación. Este precedente exhorta a una aplicabilidad directa y a un diálogo interjusrisdiccional en un compromiso formal de Derecho.

Por esto, socorrer desde teorías neoconstitucionalistas hasta globalizadores del Derecho (judicial), permiten la creación de un corpus interamericano en razón del ius cogens, en el propósito de irradiar y cumplir el compromiso social de una justicia distributiva material.

\section{REFERENCIAS}

Convención Americana de Derechos Humanos (Pacto de San José). Noviembre 7 al 22 de 1969.

25 Véase Corte Interamericana de Derechos Humanos. Sentencia de 24 DE Febrero Del 2012. (Atala Riffo y Niñas vs. Chile, febrero 24 del 2008). Párr., 90, 91,92, 93.
Corte Interamericana de Derechos Humanos. Sentencia DE 24 DE FEBRERo DEL 2012. (Atala Riffo y Niñas vs. Chile, febrero 24 del 2008).

Corte Interamericana de Derechos Humanos. Sentencia DE 26 DE NOVIEMBRe Del 2010 (Cabrera García Montiel Vs. México, noviembre 26 del 2010).

Corte Interamericana de Derechos Humanos. Sentencia DE 1 DE SEPTIEMBRE DeL 2015. (Lluy vs. Ecuador, septiembre 1 del 2015).

Daniel Torres Bayona. Criterios utilizados por la Corte Constitucional para Establecer un caTALOGO ABIERTO A LOS DERECHOS FUNDAMENTALES. Universidad Industrial de Santander. (2008).

Diego López. Teoría Impura del Derecho. Legis. (2012).

Germán J. Bidart Campos. Teoría general de los DereCHos humanos. Universidad Nacional Autónoma de México. (1989).

Holmes. Oliver The path of the LaW. Collected Papers. (1920).

Luigi Ferrajoli. Título. Editorial. (1999).

Néstor Sagüés. Obligaciones INTERNACIONALES y CONTROL DE CONVENCIONALidAd. Opus Magna. (2011).

Rodrigo Brito y Miguel Carbonell. LA GLOBALIZACión Y LOS DERECHOS HUMANOS, A LA LUZ DE LA REFORMA CONSTITUCIONAL DE JUNIO DE 2011. UNAM. (2011).

Rudolf von Thering. La LUCHA POR EL DERECHO. Trotta (2003).

Ramiro Ávila Santamaría. En Defensa del Neo constitucionalismo Andino. Corporación de Estudios y publicaciones-CEP. (2014).

Sakia Sassen. Territorio, AUtoridad y Derechos. Editorial Katz. (2010).

Sara Gordon. Ciudadanía y derechos Sociales ¿CRITERIOS DISTRIBUtivos? Clacso. (2001).

Suprema Corte de la Nación. XxviI, $1 .^{\circ}$ 10a

Tribunal Constitucional Español. sTC 29/1982 (JC, vol. III, 13 de enero de 1982).

Víctor Ferreres. UnA DEFENSA DEL MOdelo EUROPEO DE COntrol de Constitucionalidad. Editorial Macial Pons. (2011). 